\title{
SHARING ECONOMY IN RUSSIA: A POSSIBLE NEW SOURCE OF POLITICAL PARTICIPATION AND DEMOCRATIZATION? ${ }^{1}$
}

\author{
Sergey Yu. Belokonev \\ Financial University under the Government of the Russian Federation, Moscow, Russian Federation
}

Murat Z. Shogenov

Kabardino-Balkarian State University, Nalchik, Russian Federation

\section{Anzor A. Khokonov}

Financial University under the Government of the Russian Federation, Moscow, Russian Federation

\begin{abstract}
Introduction. Scientific understanding of current and future trends in the development of society, the formulation of problems of social development, and even more so its prediction is associated with the analysis of the role and place of modern and promising communication technologies in the complex architecture of social interactions. Today, such technologies determine the direction of restructuring traditional political and economic institutions contribute to the formation of fundamentally new formats of social interactions. The beginning of the $21^{\text {st }}$ century was marked by a wide spread of sharing relations - old socio-economic practices of joint (shared) use of goods in a new technical and technological design. The driver of the development of joint consumption practices has also been the spread of global trends in the transition from a system of strong fundamental links between socioeconomic entities to weaker but numerous temporary links. Methods and materials. In the course of the study, the sharing economy was considered through the prism of structural-functional, neoinstitutional and network approaches. The authors used system analysis, interdisciplinary and empirical methods (questionnaire, expert survey), as well as the method of social modeling. The materials for the study were the publications of leading foreign and domestic researchers of the issue in peer-reviewed scientific publications, as well as the results of a cross-regional sociological study conducted by the authors. Analysis. Currently, an institutional formation of a new ontological reality within which self-regulating, more autonomous from the state, sharing communities built on the network principle function is taking place. Through the liberalization of access to a wide range of benefits through low-cost channels, sharing contributes to the growth of trust, social well-being, and reduction of social tension. At the same time, the uncontrolled spread of sharing practices is fraught with a drop in the level of institutional and interpersonal trust, an increase in conflict in society, and the deformation of regional and sectoral labor markets, which will naturally affect social well-being and political stability. Results. The obtained results confirmed the hypothesis of the study that the practices of joint consumption in Russia have a pronounced o development potential and a growing influence on the political sphere through the growth of political activity of the population participating in these practices, through the actualization of microsocial contracts and the subsequent translation of their content to the macro level.
\end{abstract}

Key words: sharing economy, democracy, trust, microsocial contract, political participation, social capital.

Citation. Belokonev S.Yu., Shogenov M.Z., Khokonov A.A. Sharing Economy in Russia: A Possible New Source of Political Participation and Democratization? Vestnik Volgogradskogo gosudarstvennogo universiteta. Seriya 4. Istoriya. Regionovedenie. Mezhdunarodnye otnosheniya [Science Journal of Volgograd State University. History. Area Studies. International Relations], 2021, vol. 26, no. 5, pp. 139-150. (in Russian). DOI: https://doi.org/ 10.15688/jvolsu4.2021.5.11 


\title{
ШЕРИНГ-ЭКОНОМИКА В РОССИИ: НОВЫЙ ИСТОЧНИК ПОЛИТИЧЕСКОГО УЧАСТИЯ И ДЕМОКРАТИЗАЦИИ? ${ }^{1}$
}

\author{
Сергей Юрьевич Белоконев \\ Финансовый университет при Правительстве Российской Федерации, г. Москва, Российская Федерация
}

Мурат Замирович Шогенов

Кабардино-Балкарский государственный университет, г. Нальчик, Российская Федерация

\section{Анзор Альбертович Хоконов}

Финансовый университет при Правительстве Российской Федерации, г. Москва, Российская Федерация

Аннотация. В статье рассматриваются факторы возникновения, распространения и возможные социальные и политические последствия развития экономики совместного потребления в современной России. Анализируется трансформативный потенциал шеринг-экономики по отношению к политическим явлениям, процессам и институтам. В частности, шеринг рассматривается в качестве фактора роста политического участия, драйвера демократических процессов. По мнению авторов, становление и развитие шеринг-сообществ актуализирует необходимость внедрения принципиально новых политических технологий, применение которых, в свою очередь, будет способствовать формированию нового диалогического коммуникативного пространства в системе «власть - общество». Появление же подобного пространства станет с одной стороны индикатором, а с другой - основой для дальнейшей трансформации политической системы в сторону ее большей демократизации, в первую очередь на низовом уровне непосредственного функционирования хозяйствующих субъектов. Вклад авторов. С.Ю. Белоконев - общий дизайн исследования, проведение экспертного опроса, составление структуры публикации. М.З. Шогенов - формирование программы и проведение социологического исследования, анализ и интерпретация результатов исследования, написание отдельных блоков текста. А.А. Хоконов - подготовка аналитической части работы, написание отдельных блоков текста. Подготовка статьи - С.Ю. Белоконев, М.З. Шогенов, А.А. Хоконов.

Ключевые слова: шеринг-экономика, демократия, доверие, микросоциальный контракт, политическое участие, социальный капитал.

Цитирование. Белоконев С. Ю., Шогенов М. З., Хоконов А. А. Шеринг-экономика в России: новый источник политического участия и демократизации? // Вестник Волгоградского государственного университета. Серия 4, История. Регионоведение. Международные отношения. - 2021. - Т. 26, № 5. - С. 139-150. - DOI: https://doi.org/10.15688/jvolsu4.2021.5.11

Введение. В начале XXI в. идеология сверхпотребления, доминировавшая в массовом сознании долгие десятилетия, столкнулась с естественными и очевидными ограничениями в виде исчерпания сырьевых ресурсов, общей деградации естественных экосистем, наблюдающейся во всем мире эрозии среднего класса и углубления имущественной дифференциации. Все обозначенное актуализировало необходимость появления новых моделей общественно-политического развития, базирующихся на концепции справедливого распределения благ, в основе которой лежит идея использования потребительских свойств блага (юр. пользование) без приобретения права собственности (юр. владение). Таким образом, сформировались условия для широкого, многовекторного распространения шеринг-экономики - старых социально-экономических практик совместного (долевого) пользования благами в новом технико-технологическом оформлении [2]. Осмысление указанных процессов в социальных и политических науках привело к появлению термина «политический консюмеризм». Политически мотивированное потребление рассматривается как переход от пассивного индивидуалистского к активному осознанному, ориентированному на общественное благополучие, при этом рынок становится пространством восстанов- 
ления социальной справедливости через новые формы политического участия [9].

Методы и материалы. В ходе проведенного исследования шеринг-экономика рассматривалась через призму структурно-функционального, неоинституционального и сетевого подходов. В работе были использованы системный анализ, междисциплинарный и эмпирические методы (анкетирование, экспертный опрос), а также метод социального моделирования. Материалами для исследования послужили публикации ведущих зарубежных и отечественных исследователей вопроса в рецензируемых научных изданиях, а также результаты кроссрегионального эмпирического исследования, проведенного авторами.

Анализ. Доверие, сотрудничество и демократическое развитие. При изучении различных аспектов функционирования шеринг-экономики на первый план исследовательского интереса всегда выходят вопросы, связанные с доверием, сотрудничеством и уровнем социального капитала. Это обусловлено тем, что высокая степень доверия является ключевым источником дохода в шерингэкономике и параллельно одним из важнейших элементов системы ее саморегуляции. При том, что в деятельности шеринг-сообществ, по мнению Е.С. Земсковой, саморегуляция играет значительно более важную роль, чем государственное регулирование [4].

Американский политолог Р. Патнэм в работе «Чтобы демократия работала: Гражданские традиции в современной Италии» [23] связал экономическое развитие и успешность демократизации государственного управления с уровнем социального капитала в обществе. Он определил роль превалирования горизонтальных связей в сообществе для воспроизводства социального капитала, необходимого в дальнейшем для выстраивания политических и социальных взаимодействий и повышения эффективности деятельности органов власти. Исследования, проведенные позже С. Кнэк и Ф. Кифер [20], выявили положительную корреляцию темпов экономического роста и эффективности государственной бюрократии в странах с высоким уровнем доверия.

Ряд исследований подтверждает взаимосвязь высокого уровня социального капитала с более эффективным производством и управ- лением общественными благами на уровне отдельных сообществ. Примерами могут служить исследования особенностей управления ресурсами общего доступа (земельные, водные, лесные и т. д.) [22] и коллективной собственностью жилых домов [25], которые показали, что издержки по организации коллективных действий меньше в сообществах, где ее члены разделяют общие ценности и вступают на этой основе в кооперацию. «Эти данные характеризует эффективность институтов самоорганизации, которые влияют на благосостояние конкретного сообщества через повышение уровня доверия, социальной и гражданской активности его членов» [5]. Аналогичное исследование, проведенное в России Л.И. Полищук, А.А. Пересецким и Е.Н. Борисовой, привело авторов к выводу, что одним из главных препятствий коллективного управления жилыми домами в российских городах является низкая склонность граждан к самоорганизации и участию в различных коллективных действиях [8].

Связь уровня социального капитала с эффективностью государственной бюрократии, выраженной в степени подотчетности органов власти подтверждается рядом кейсов в итальянских регионах. Так, наличие выраженной связи между уровнем социального капитала и развитием демократических процессов определено в работах Г. Табеллини [21].

Низкое качество формальных институтов управления является одним из следствий дефицита социального капитала, поскольку сообщества, характеризующиеся низким уровнем солидарности, артикулируют спрос на внешнее (государственное) управление, не имея при этом возможности осуществлять гражданский контроль, то есть имеет место выраженная зависимость - чем ниже степень доверия и солидарности в обществе, тем больше пространства для неконтролируемого государства. Подобная ситуация является коррупциогенной и в дальнейшем способствует падению эффективности системы распределения общественных благ и снижению эффективности деятельности государственных органов [11].

Повышение уровня солидарности в обществе на основе потребностно ориентирован- 


\section{РЕГИОНАЛЬНЫЕ СТРАТЕГИИ И ПРИОРИТЕТЫ}

ной идентичности способствует повышению социальных экспектаций к органам власти. Прямая зависимость между уровнем политического участия (определяемого на основе явки на выборах) и уровнем социального капитала подтверждена, в частности, в работах, посвященных периоду становления и развития демократических традиций в Италии в конце XIX - начале XX в. [18].

Важным направлением исследований социального капитала и его динамики является изучение механизмов его воспроизводства в ходе индивидуального опыта и трансмиссии в процессе социализации. Результаты исследования практик микрофинансирования в Индии [15], предполагающих коллективную ответственность, подтвердили, что одним из факторов роста уровня доверия и формирования норм кооперации является плотность и частота социальных взаимодействий.

Шеринг-экономика как новый источник социального капитала и практик сотрудничества. Для объяснения сотрудничества в рамках шеринг-экономики наиболее перспективным является рациональный подход к интерпретации природы доверия, принимая во внимание такие ключевые типологические характеристики экономики совместного пользования, как: 1) возможность вступать в обмен с ранее незнакомыми людьми благодаря новым источникам доверия, не связанным с локальным социальным и культурным капиталом; 2) цифровые информационные технологии, обеспечивающие мгновенный краудсорсинг репутационной информации об участниках [24].

В шеринг-экономике условия сотрудничества возникают благодаря повторяющимся в неопределенной перспективе взаимодействиям, множественности транзакций, возможности получения выгоды каждым из участников, а также скорости коммуникации, формирующей репутационный капитал. Доступные для всех участников индивидуальные профили и страхование сделок создают условия для их безопасности и роста доверия. Исследования показывают, что люди склонны доверять групповым рейтингам продуктов и услуг, то же самое справедливо и в отношении оценок отдельных людей. Пока у участников есть стимулы избегать необоснованного со- трудничества из-за угрозы получения плохих отзывов и возникновения репутационных рисков, шеринг-платформа будет воспроизводить сценарии сотрудничества и минимизировать появление других сценариев [10].

В рассматриваемом контексте интерес для политической науки прежде всего представляет вопрос, имеет ли опыт сотрудничества и репутационный капитал участников обмена, возникающий в рамках шеринг-сообществ, потенциал к трансформации в иные формы сотрудничества. Отдельными исследователями оспаривается символическое значение накопленного группой социального капитала, то есть признание его другими социальными группами в качестве легитимной компетенции, достаточной для вступления в межгрупповое сотрудничество в иных сферах общественных отношений, в частности в гражданском и политическом секторах. Между тем, сегодня все большее число гражданских активистов, членов социальных движений становятся активными участниками шерингпрактик, определяя процесс их распространения в качестве фактора развития политического участия (низовая гражданская активность) в будущем. Прецеденты трансформации опыта шеринг-сотрудничества в модели гражданского и политического участия, сотрудничества граждан, объединенных территориальным признаком и общностью интересов, выходящих за рамки экономического обмена, уже существуют и представляют значительный исследовательский интерес.

Существующие шеринг-платформы потенциально могут управляться пользователями и быть в кооперативной собственности. В свою очередь, институты и организации гражданского общества, союзы, социальные группы могут создавать собственные платформы для достижения общественных и политических эффектов сотрудничества, направленных на перераспределение благ, стимулирование гражданского участия, защиту экологии и укрепление социальных связей. Д. Шор утверждает, что способность новых шерингпрактик выступать инструментом преодоления социального неравенства зависит от перспектив их трансформации в социальные движения муниципального уровня - чем больше подобная вероятность, тем больше и вероят- 
ность достижения указанных целей [26]. По ее мнению, технологии, которые лежат в основе шеринга и позволяют обмениваться информацией, создавать социальные связи и кооперацию с ранее незнакомыми людьми, социально трансформативны и представляют собой мощнейший инструмент формирования социальной солидарности, фактор демократизации публичной власти на всех уровнях.

"Чрезвычайное государство» (the state of exception), публичное пространство и шеринг-экономика. Для объяснения возможных причин развития шеринг-экономики в России как перспективного фактора демократизации политической системы можно обратиться к концепции сфер суверенитетов Е.С. Алексеенковой и В М. Сергеева [1]. Данные авторы внутри одного социально-политического поля выделяют три сферы суверенитетов: индивида, государства и сферу отсутствия суверенитета - публичную. Суверенитет индивида определяется как эквивалент понятия «приватная сфера» (privacy) - пространство функционирования саморегулирующегося субъекта. В приватной сфере государства политика реализуется через неформальные сети (представители лоббистских групп среди чиновников и др.) и латентные формы взаимодействия участников (сотрудники спецслужб), а также в период различных «чрезвычайных» ситуаций, не регулируемых формальными институтами. В условиях такой «чрезвычайности» трансформируются границы суверенитетов, а следовательно, и структура взаимодействия индивида и государства.

Современная российская общественнополитическая действительность демонстрирует все признаки стремительного сокращения публичного пространства и расширения приватной сферы государства. Количество зон, внутри которых индивиду неизвестны правила взаимодействия, а власть остается антропологическим фактом, не имеющим институциональные ограничения, растет. Это зоны отсутствия публичной сферы, а, следовательно, отсутствия гарантий контролируемого функционирования социальных норм и институтов [1]. В соответствии с этим растущее участие граждан в шеринг-сообществах можно рассматривать как выбор некой стратегии, которая позволяет не только сохранить внутрен- нюю субъектность индивида при сохранении подвластности, но и сформировать необходимое для его выживания публичное пространство в измерении недоступном для «нормирующего» государства.

Т. Дональдсон и Т. Данфи [13] в своей интегральной теории социальных контрактов предлагают понятие свободного морального пространства как сферы микросоциальных контрактов, затрагивающих потребности конкретных сообществ и наилучшим образом служащих их интересам, но не регулируемых напрямую макросоциальным контрактом [2]. Концепт свободного морального пространства можно рассматривать как эквивалент понятия приватной сферы Е.С. Алексеенковой и В.М. Сергеева, но на уровне отдельных сообществ. Государство, в соответствии с таким подходом, может рассматриваться, как сфера макросоциального контракта, а микросоциальный контракт - как локальная и эксклюзивная для членов сообществ версия публичной сферы - сферы суверенитета норм, сформированных в результате частных соглашений субъектов данного сообщества. В условиях растущего структурного насилия со стороны государства не только сохраняется, но и возрастает актуальность ценностей выживания, которые стимулируют поиск гражданами новых способов удовлетворения базовых потребностей, в том числе, через объединение в различные шеринг-сообщества. В ситуации всеобщего кризиса доверия новые формы кооперации нуждаются в альтернативных его источниках, необходимых для обеспечения сотрудничества в интереcax всех и каждого. Появление сообществ по Т. Дональдсону и Т. Данфи связанно с перспективой конфликта норм и необходимостью определения приоритетов. Одним из ключевых критериев определения приоритетности нормы является ее значимость для поддержания среды, в которой происходит обмен, перед нормами, потенциально разрушительными для этой среды. «Конфликт норм, в рассматриваемом контексте, может быть рассмотрен в связи с растущими объемами участия граждан в шеринг-сообществах и потенциальной приоритетностью норм локальных микросоциальных контрактов над нормами макросоциального» [2], условия и требова- 
ния, которого становятся все менее понятными, прозрачными и гарантированными в «чрезвычайном» государстве, вытесняющем собой публичное пространство на макроуровне. Доминирование в российских условиях норм микросоциальных контрактов над положениями макросоциального связано и с отсутствием в массовом сознании представления о безусловной взаимосвязи «благо для государства - благо для граждан». В сумме обозначенные факторы обуславливают дистанцирование широких масс общества от политики. В политической социологии подобная ситуация получила название «негативный консенсус общества и власти - мы вас не трогаем, и вы нас не трогайте, мы от вас ничего не ждем, но и вы не лезьте в наши дела. Этот негативный консенсус на самом деле и послужил основой, так называемой путинской стабильности» [3].

В этих условиях граждане вынуждены искать альтернативные способы решения актуальных для них проблем, не предполагающие сотрудничество с властными структурами.

Результаты экспертного опроса проведенного в рамках исследования «Экономика совместного пользования, социальный капитал и политические инстиmymbl». Для изучения перспектив шеринга как фактора роста доверия, политического участия, авторами было разработано и проведено кроссрегиональное эмпирическое исследование. Полевая часть исследования, включившего в себя анкетирование пользователей услуг шеринг-платформ (подбор респондентов на основе таргетированной рекламы) и экспертный опрос, была проведена в октябpe - ноябре 2019 года.

Анализ непосредственно политических аспектов (трансформация политических институтов, рост политического участия) развития шеринг-экономики проводился в непосредственной увязке с социально-экономическими процессами и явлениями. Совместное потребление благ рассматривалось как глубоко политизированный процесс, как проявление политического консьюмеризма, формы политического участия, ориентированного на преодоление социальной несправедливости в пространстве рынка по- средством осознанного коллективного потребления.

Вопросы, использованные для экспертного опроса, охватывали широкий круг проблем, связанных с распространением экономики совместного пользования. В то время как ответы на другие вопросы должны были показать контекст развития шеринг-практик в России (политический, социально-экономический, культурный) и отношение в целом к шерингу, ответы на вопросы № 1, 2, 7, 11, 12 должны были отразить мнение экспертного сообщества относительно ключевой составляющей гипотезы проведенного исследования - трансформативного потенциала шерингпрактик по отношению к политическим процессам и институтам.

Первый блок вопросов был направлен на выявление общего мнения экспертов о дальнейшем развитии экономики совместного пользования в России. По мнению большинства экспертов, в дальнейшем шеринг-практики продолжат развитие, расширяя сферы своего присутствия $-75 \%$. Часть экспертов $25 \%$ считает, что шеринг-практики будут развиваться скачкообразно, в зависимости от конкретного социально- экономического контекста и технико-технологических условий (см. рис. 1). Считающих, что шеринг-практики столкнутся с естественными ограничениями (не со стороны органов власти) и перестанут развиваться среди опрошенных не оказалось.

Часть экспертов - 41,7 \% отвечая на вопрос о роли государства в экономике совместного пользования, отметила, что государство должно полностью абстрагироваться от шеринг-практик, потому как шеринг-сообществам имманентно присущи механизмы саморегуляции и дополнительная внешняя регуляция в данном случае будет избыточной (см. рис. 2). По мнению большей части экспертов 58,3 \% государство должно стать регулятором шеринг-процессов в стране, осуществляя законодательную и контрольно-надзорную деятельность, но при этом не реализуя прямое административное воздействие. Считающих, что государство должно ограничивать деятельность шеринг-сервисов и их распространение из-за исходящих от них явных угроз общественной безопасности среди опрошенных не оказалось. 


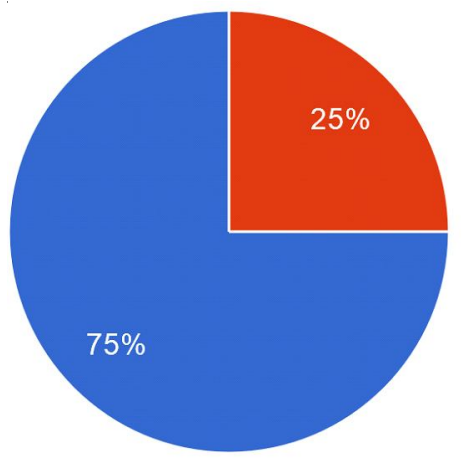

Да, шеринг практики продолжат развитие, так как это прогрессивная модель удовлетворения потребностей об...

Шеринг практики будут то «затухать», то появляться вновь в зависимости от появления и проникновения новых информац...

Шеринг практики в ближайшее время столкнутся с ограничениями и прекратят развиваться, возмо...

Рис. 1. Распределение ответов на вопрос № 1 «Как вы думаете, шеринг-практики продолжат многовекторное распространение или в ближайшее время столкнутся с естественными ограничениями (не со стороны государства)?»

Fig.1. Distribution of answers to question No. 1 "Do you think sharing practices will continue to spread in a multi-vector manner or face natural restrictions (not from the state) in the near future?"

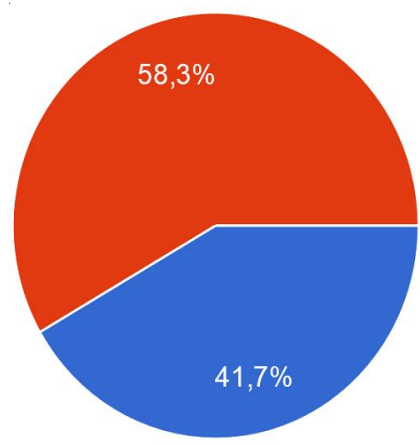

Государство должно полностью абстрагироваться от шерингпрактик. Шеринг-сообществам имманентно присущи механизм...

Государство должно установить четкие «правила игры» и осуществлять контроль и надзор за деятельностью шеринг-сервисов

Государство должно ограничивать деятельность шеринг-сервисов и их распространение, из-за исход..

Рис. 2. Распределение ответов на вопрос № 2 «Как Вы думаете, какой должна быть роль государства в развитии шеринг-практик?»

Fig. 2. Distribution of answers to question No. 2 "What do you think should be the role of the state in the development of sharing practices?"

При этом, по мнению экспертов, основными препятствиями на пути развития шерингпрактик будут: относительно невысокая безопасность сделок; неуверенность пользователей в качестве предоставляемых товаров и услуг; отсутствие полноценной правовой базы шеринг-платформ, которая бы позволила пользователям чувствовать себя увереннее.

Больше половины респондентов - 66,7 \% считает, что именно развитие шеринг-сервисов в условиях отсутствия иных источников, благодаря высокой степени межличностного взаимодействия и растущей потребностно ориентированной идентичности будет одним из факторов роста доверия в России (см. рис. 3). $8,3 \%$ экспертов, акцентируя внимание на небезопасности сделок между гражданами в нерегулируемом пространстве, считают, что шеринг-практики рано или поздно приведут к па- дению доверия, так как пространство шеринга представляет собой одно большое поле для злоупотреблений и на определенном этапе в зависимости от типа поведения участников каждый (по Р. Аксельроду) [13] столкнется с недобросовестностью другого участника (предлагающего благо ненадлежащего качества). $25 \%$ опрошенных затруднились с ответом на данный вопрос.

Большая часть экспертов - 85,3 \% считает, что всестороннее вовлечение в сферу шеринга будет влиять на рост политической активности населения. При этом 24,4 \% опрошенных считает, что граждане получат опыт решения проблем своими силами, что повлечет значительный рост их политической активности. $60,9 \%$ экспертов считают, что влияние на политическую активность будет иметь место, но данное влияние будет незна- 


\section{РЕГИОНАЛЬНЫЕ СТРАТЕГИИ И ПРИОРИТЕТЫ}

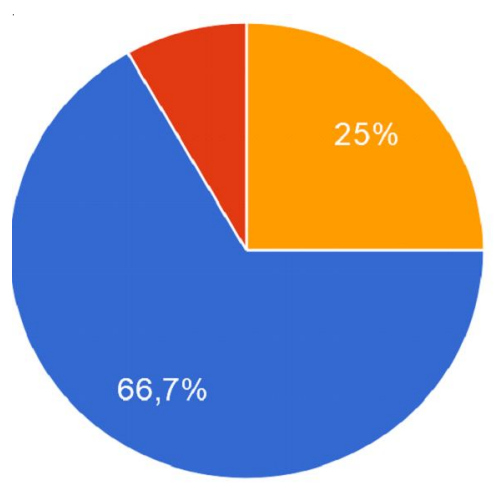

Да, так как сервисы предполагают высокую степень взаимодействия людей друг с другом

Нет, так как шеринг-практики представляют собой одно большое пространство для злоупотреблений

Затрудняюсь ответить

Рис. 3. Распределение ответов на вопрос № 7 «Как Вы думаете, будут ли шеринг-сервисы способствовать росту доверия в нашей стране?»

Fig. 3. Distribution of answers to question No. 7 "Do you think sharing services will contribute to the growth of trust in our country?"

чительным. 7,3\% опрошенных считает, что именно частная собственность со всеми вытекающими правовыми последствиями является базисным фактором политической активности граждан. Еще 7,3 \% респондентов затруднились с ответом (см. рис. 4).

Большинство экспертов - 66,7 \% считает, что многовекторное распространение практик совместного использования благ (ресурсы, инфраструктурные объекты) станет фактором трансформации традиционных политических институтов уже в среднесрочной перспективе. По мнению опрошенных в первую очередь изменения коснутся местного самоуправления в сторону наполнения его реальным функционалом и института представительства. Из них $16,7 \%$ считают, что шеринг станет детерминантой политического развития и фактором коренной трансформации политических институтов. Ровно половина опрошенных экспертов считает, что политические институты будут меняться под воздействием проникновения шеринг-практик во все сферы общества, но характер этих изменений не будет иметь определяющего значения по отношению к российскому политическому процессу. И лишь $25 \%$ опрошенных отметили отсутствие выраженных причинно-следственных связей между развитием шеринг-экономики, ростом политической активности и трансформацией политических институтов (см. рис. 5).

Результаты кроссрегионального эмпирического исследования подтвердили гипотезу, что практики совместного потребления имеют в России выраженный потенциал развития и обладают растущим влиянием на политическую сферу через рост политической активности населения - участников этих практик.

Благодаря либерализации доступа к широкой линейке благ через низкозатратные каналы шеринг способствует росту доверия и социального благополучия, а также сокращению уровня социальной напряженности. Вместе с тем бесконтрольное распространение шеринг-практик чревато падением уровня институционального и межличностного доверия, ростом конфликтности в социуме, деформацией региональных и отраслевых рынков труда, что естественным образом отразится на социальном самочувствии и политической стабильности.

В российском обществе сегодня складывается конфликт, в котором с одной стороны общество демонстрирует низкий уровень межличностного доверия, выражающийся в отсутствии гражданской самоорганизации, политическом абсентеизме и вере в государствопатерналиста, а с другой - власть демонстрирует низкую эффективность государственной бюрократии, растущее структурное насилие в условиях «чрезвычайности» («темный колодец власти»), что сопровождается приватизацией власти ее носителями на местах, схлопыванием публичного пространства и отсутствием гарантий контролируемого функционирования социальных норм и институтов, производства и распределения общественных благ (односторонний пересмотр общественного договора и самоустранение от социальных обязательств со стороны власти). 


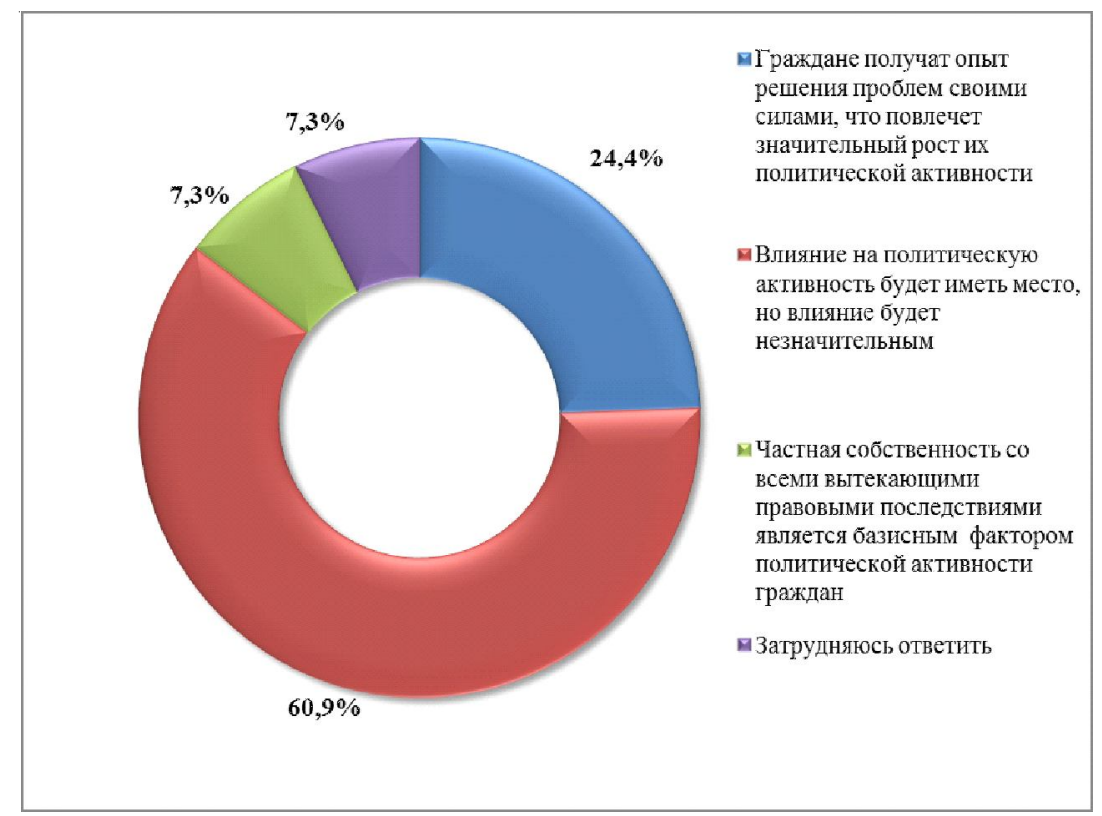

Рис. 4. Распределение ответов на вопрос № 11 «Экономическая независимость и самостоятельность граждан, базирующаяся на защищенной частной собственности является основой развития гражданского общества. Благодаря участию в шеринг-практиках граждане получают, с одной стороны, доступ к большей номенклатуре благ с минимальными издержками, а с другой стороны, учатся самостоятельно без помощи государства удовлетворять свои потребности,

не приобретая собственность. Как Вы думаете, будет ли участие в шеринг-практиках способствовать росту политической активности населения?»

Fig. 4. Distribution of answers to question No. 11 "Economic independence and independence of citizens based on protected private property is the basis for the development of civil society. Through participation

in sharing practices, citizens, on the one hand, get access to a larger range of goods at minimal cost, and on the other hand, learn to meet their own needs without the help of the state, without acquiring property.

Do you think participation in sharing practices will contribute to the growth of political activity of the population?"

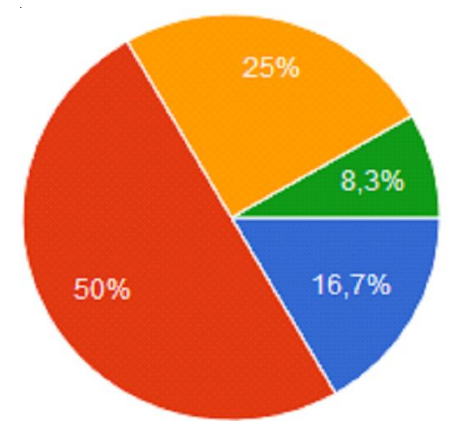

Несомненно, распространение шеринг-практик будет способствовать трансформации..

Да, политические институты трансформируются, но незначительно

Нет, влияние шеринг-практик слишком невелико для трансформации таких устоявшихс. Затрудняюсь ответить

Рис. 5. Распределение ответов на вопрос № 12 «Считаете ли Вы, что дальнейшее распространение шеринг-практик повлечет трансформацию “традиционных” политических институтов (представительства, местное самоуправление и т. д.) и появление новых политических институтов?»

Fig. 5. Distribution of answers to question No.2 "Do you think further spread of sharing practices will lead to the transformation of 'traditional' political institutions (representative offices, local self-government, etc.) and the emergence of new political institutions?" 


\section{РЕГИОНАЛЬНЫЕ СТРАТЕГИИ И ПРИОРИТЕТЫ}

В этих условиях широкое, многовекторное распространение практик совместного пользования имеет значительный потенциал влияния на политические процессы, параметры функционирования традиционных и складывающихся социальных институтов, демократизацию политической системы в целом, через актуализацию микросоциальных контрактов и последующую трансляцию их содержания на макроуровень [2]. В связи с этим особую актуальность приобретают проблемы изучения сообществ шеринг-экономики как формирующегося структурного элемента российского общества в рамках «политэкономии небольших анонимных сообществ», институционализация которых происходит здесь и сейчас.

\section{ПРИМЕЧАНИЯ}

${ }^{1}$ Статья подготовлена при финансовой поддержке Российского фонда фундаментальных исследований. Проект 19-011-31495 «Факторы, содержание и сценарии трансформации политических институтов в условиях развития экономики совместного потребления (sharing economy) и сетевых информационных технологий».

The article was prepared with the financial support of the Russian Foundation for basic research. Project 19-011-31495 «Factors, content and scenarios of transformation of political institutions in the context of the development of the sharing economy and network information technologies».

${ }^{2}$ Основные результаты анкетирования находятся в свободном доступе [10].

${ }^{3}$ Учитывая относительно слабую разработанность проблематики шеринг-экономики в российской науке, в качестве экспертов в рамках экспертного опроса выступили отечественные ученые, имеющие одну или более публикаций в рецензируемых научных изданиях по соответствующей теме. Экспертным опросом было охвачено 36 исследователей (социологи, политологи, экономисты) и 5 специалистов практиков (организаторы шеринг-экономических проектов).

${ }^{4}$ Низкий уровень социального доверия в Российской Федерации подтверждается результатами многочисленных исследований реализованных в рамках World Value Survey, European Social Survey и International Social Survey Programme. Россия по данному показателю традиционно занимает последние места и в рейтинге Trust Barometer формируемом компанией Edelman.

\section{СПИСОК ЛИТЕРАТУРЫ}

1. Алексеенкова, Е. С. Темный колодец власти (о границе между приватной сферой государства и приватной сферой личности) / Е. С. Алексеенкова, В. М. Сергеев // Полис. - 2008. - № 3. - С. 148-165.

2. Белоконев, С. Ю. Социальные эффекты совместного потребления (sharing economy): сетевые экономические и политические сообщества / С. Ю. Белоконев, А. А. Хоконов, М. 3. Шогенов // Власть. -2019. - Т. 27, № 6. - С. 115-123.

3. Голубева, Т. Г. К вопросу о политических условиях введения местного самоуправления в современной России / Т. Г. Голубева // Государственное и муниципальное управление. Ученые записки СКАГС. - 2009. - № 3. - С. 131-143.

4. Земскова, Е. С. Шеринг как отражение ценностных ориентиров потребителя в цифровой экономике / Е. С. Земскова // Научный журнал НИУ ИТМО. Серия: Экономика и экологический менеджмент. - 2019. - № 3. - С. 17-27.

5. Иванов, В. В. Формирование социального капитала в России / В. В. Иванов, П. Н. Павлов, В. А. Козлов, Т. А. Сутырина // Вестник московского университета. Серия 6, Экономика. - 2014. № 3. - C. 3-16.

6. Максимов, В. «Для людей это шоу»: Россияне воспринимают политику как развлечение, не влияющее на их жизнь / В. Максимов // Новые известия. $-2005 .-27$ дек.

7. Полищук, Л. И. Экономическое значение социального капитала / Л. И. Полищук, Р. Ш. Меняшев // Вопросы экономики. - 2011. - № 12. C. $46-65$.

8. Полищук, Л. И. Управление коллективной собственностью в российских городах: анализ товариществ собственников жилья / Л. И. Полищук, А. А. Пересецкий, Е. Н. Борисова // Вопросы экономики. -2010 . - № 11. - С. 115-135.

9. Романова, Р. И. Что политического в потреблении? / Р. И. Романова // Экономическая социология. -2018 . - Т. 19. - № 1. - С. 168-187.

10. Шогенов, М. 3. Шеринг-экономика, доверие и политическое участие в современном информационном обществе: по материалам социологического исследования / М. З. Шогенов, А. А. Хоконов // Электронный журнал «Кавказология». 2019. - № 4. - C. 128-152. - DOI: https://doi.org/ 10.31143/2542-212X-2019-4-128-152.

11. Aghion, P. Regulation and Distrust / P. Aghion, Y. Algan, P. Cahuc // The Quarterly J. of Economics. - 2010. - Vol. 125. - No. 3. - P. 1015-1049.

12. Algan, Y. Teaching Practices and Social Capital /Y. Algan, P. Cahuc, A. Shleifer // American Economic Journal: Applied Economics. - 2013. - No. 5 (3). P. 189-210. 
13. Axelrod, R. The Evolution of Cooperation / R. Axelrod. - New York : Basic Books, 1984. - 241 p.

14. Donaldson, T. Ties That Bind: A Social Contracts Approach to Business Ethics / T. Donaldson, T. W. Dunfee. - Cambridge : Harvard Business School Press, 1999. $-306 \mathrm{p}$.

15. Feigenberg, B. The Economic Returns to Social Interaction: Experimental Evidence from Microfinance / B. Feigenberg, E. Field, R. Pande // Rev. of Economic Studies. - 2013. - Vol. 80, no. 4. P. 1459-1483.

16. Fisher, G. Beyond Binary Choices: Integrating Individual and Social Creativity / G. Fisher, E. Giaccardi, H. Eden // International Journal of Human-Computer Studies (IJHCS). - 2005. - No. 12. - P. 428-512.

17. Glaeser, E. Why Does Democracy Need Education? / E. Glaeser, G. Ponzetto, A. Shleifer // J. of Economic Growth. - 2007. - Vol. 12, no. 2. - P. 77-99.

18. Guizo, L. Democratization and Civic Capital / L. Guizo, P. Pinotti // CEPR Discussion Paper. - 2012. No. 8847. - Electronic text data. - Mode of access: https://ssrn.com/abstract=2013840 (date of access: 08.02.2020). - Title from screen.

19. Helliwell, J. Education and Social Capital / J. Helliwell, R. Putnam // Eastern Economics J. 2007. - No. 1. - P. 1-19.

20. Knack, S. Does Social Capital Have an Economic Payoff? A Cross Country Investigation / S. Knack, Ph. Keefer // Quarterly J. of Economics. - 1997. Vol. 112. -No. 4. -P. 1251-1288.

21. Nannicini, T. Social Capital and Political Accountability / T. Nannicini, A. Stella, G. Tabellini // FEEM Working Paper. - 2010. - No. 58. Electronic text data. - Mode of access: https://ssrn. com/abstract $=1622136$ (date of access: 18.02 .2020 ). Title from screen.

22. Ostrom, E. Collective Action and the Evolution of Social Norms / E. Ostrom // J. of Economic Perspectives. - 2000. - Vol. 14, no. 3. - P. 137-158.

23. Putnam, R. Making Democracy Work. Civic Traditions in Modem Italy / R. Putnam, R. Leonardi, R. Nanetti. - New Jersey : Princeton University Press, 1993. $-122 \mathrm{p}$.

24. Reisch, L. A. Handbook on Research on Sustainable Consumption / L. A. Reisch, J. Thogersen. Cheltenham : Edward Elgar Publishing, 2015. - 488 p.

25. Saegert S. Social Capital and the Revitalization of New York City's Distressed Inner-City Housing / S. Saegert, G. Winkel // Housing Policy Debate. 1998. - Vol. 9, no. 1. - P. 17-61.

26. Schor, J. Debating the Sharing Economy/J. Schor // Great Transition Initiative. - 2014. - Electronic text data. Mode of access: https:/www.greattransition.org/ publication/debating-the-sharing-economy (date of access: 11.01.2020).- Title from screen.

\section{REFERENCES}

1. Alekseenkova E.S., Sergeev V.M. Temnyj kolodec vlasti (o granice mezhdu privatnoj sferoj gosudarstva i privatnoj sferoj lichnosti) [The Dark Well of Power (About the Border Between the Private Sphere of the State and the Private Sphere of the Individual)]. Polis, 2008, no. 3, pp. 148-165.

2. Belokonev S.Yu., Khokonov A.A., ShogenovM.Z. Social'nye effekty sovmestnogo potrebleniya (sharing economy): setevye ekonomicheskie i politicheskie soobshchestva [Social Effects of Shared Consumption (Sharing Economy): Network Economic and Political Communities]. Vlast', 2019, vol. 27, no. 6, pp. 115-123.

3. Golubeva T.G. K voprosu o politicheskih usloviyah vvedeniya mestnogo samoupravleniya $\mathrm{v}$ sovremennoj Rossii [On the Question of the Political Conditions for the Introduction of Local Self-Government in Modern Russia]. Gosudarstvennoe i municipal'noe upravlenie. Uchenye zapiski SKAGS, 2009, no. 3,pp. 131-143.

4. Zemskova E.S. Shering kak otrazhenie cennostnyh orientirov potrebitelya $\mathrm{v}$ cifrovoj ekonomike [Sharing As a Reflection of the Consumer's Value Orientations in the Digital Economy]. Nauchnyj zhurnal NIU ITMO. Seriya: Ekonomika $i$ ekologicheskij menedzhment, 2019, no. 3, pp. 17-27.

5. Ivanov V.V., Pavlov P.N., Kozlov V.A., Sutyrina T.A. Formirovanie social'nogo kapitala v Rossii [Formation of Social Capital in Russia]. Vestnik moskovskogo universiteta. Seriya 6, Ekonomika, 2014, no. 3, pp. 3-16.

6. Maksimov V. «Dlya lyudej eto shou»: Rossiyane vosprinimayut politiku kak razvlechenie, ne vliyayushchee na ih zhizn' ["This is a Show for People": Russians Perceive Politics As Entertainment that Does Not Affect Their Lives]. Novye izvestiya, 2005, December 27.

7. Polishchuk L.I., Menyashev R.Sh. Ekonomicheskoe znachenie social'nogo kapitala [The Economic Significance of Social Capital]. Voprosy ekonomiki, 2011, no. 12, pp. 46-65.

8. Polishchuk L.I., Pereseckij A.A, Borisova E.N. Upravlenie kollektivnoj sobstvennost'yu v rossijskih gorodah: analiz tovarishchestv sobstvennikov zhil'ya [Collective Property Management in Russian Cities: Analysis of Homeowners' Associations]. Voprosy ekonomiki, 2010, no. 11, pp. 115-135.

9. Romanova R.I. Chto politicheskogo v potreblenii? [What is Political About Consumption?]. Ekonomicheskaya sotsiologiya, 2018, vol. 19, no. 1. pp. 168-187.

10. Shogenov M.Z., Khokonov A.A. Sheringekonomika, doverie i politicheskoe uchastie v sovremennom informacionnom obshchestve: po materialam sociologicheskogo issledovaniya [Sharing Economy, Trust and Political Participation in Modern Information Society: Based on Sociological Survey Materials]. Elektronnyj zhurnal «Kavkazologiya», 2019, no. 4, pp. 128-152. DOI: https://doi.org/10.31143/2542-212X-2019-4-128-152. 
11. Aghion P., Algan Y., Cahuc P. Regulation and Distrust. The Quarterly J. of Economics, 2010, vol. 125, no. 3, pp. 1015-1049.

12. Algan Y., Cahuc P., Shleifer A. Teaching Practices and Social Capital. American Economic Journal: Applied Economics, 2013, no. 5(3), pp. 189-210.

13. Axelrod R. The Evolution of Cooperation. New York, Basic Books, 1984. 241 p.

14. Donaldson T., Dunfee T.W. Ties That Bind: A Social Contracts Approach to Business Ethics. Cambridge, Harvard Business School Press, 1999, 306 p.

15. Feigenberg B., Field E., Pande R. The Economic Returns to Social Interaction Experimental Evidence from Microfinance. Rev. of Economic Studies, 2013, vol. 80, no. 4, pp. 1459-1483.

16. Fisher G., Giaccardi E., Eden H. Beyond Binary Choices: Integrating Individual and Social Creativity. International Journal of Human-Computer Studies (IJHCS), 2005, no. 12, pp. 428-512.

17. Glaeser E., Ponzetto G., Shleifer A. Why Does Democracy Need Education? J. of Economic Growth, 2007, vol. 12, no. 2, pp. 77-99.

18. Guizo L., Pinotti P. Democratization and Civic Capital. CEPR Discussion Paper, 2012, no. 8847. URL: https://ssrn.com/abstract=2013840 (accessed 8 February 2020).
19. Helliwell J., Putnam R. Education and Social Capital. Eastern Economics J, 2007, no. 1, pp. 1-19.

20. Knack S., Keefer Ph. Does Social Capital Have an Economic Payoff? ACross Country Investigation. Quarterly J. of Economics, 1997, vol. 112, no. 4, pp. 1251-1288.

21. Nannicini T., Stella A., Tabellini G. Social Capital and Political Accountability. FEEM Working Paper No. 58, 2010. URL: https://ssrn.com/ abstract $=1622136$ (accessed 18 February 2020).

22. Ostrom E. Collective Action and the Evolution of Social Norms. J. of Economic Perspectives, 2000, vol. 14, no. 3, pp. 137-158.

23. Putnam R., Leonardi R., Nanetti R. Making Democracy Work. Civic Traditions in Modem Italy. New Jersey, Princeton University Press, 1993. 122 p.

24. Reisch L.A., Thogersen J. Handbook on Research on Sustainable Consumption. Cheltenham, Edward Elgar Publishing, 2015. 488 p.

25. Saegert S., Winkel G. Social Capital and the Revitalization of New York City's Distressed InnerCity Housing. Housing Policy Debate, 1998, vol. 9, no. 1, pp. 17-61.

26. Schor J. Debating the Sharing Economy. Great Transition Initiative, 2014. URL: https://www. greattransition.org/publication/debating-the-sharingeconomy (accessed 11 January 2020).

\section{Information About the Authors}

Sergey Yu. Belokonev, Candidate of Sciences (Politics), Academic Adviser of Faculty of Social Sciences and Mass Communications, Financial University under the Government of the Russian Federation, Prosp. Leningradsky, 49, 125993 Moscow, Russian Federation, departpol@mail.ru, https://orcid.org/0000-0002-8028-7421

Murat Z. Shogenov, Candidate of Sciences (Psychology), Associate Professor, Senior Researcher of Center for Sociological Research, Kabardino-Balkarian State University, Chernyshevskogo St, 173, 360004 Nalchik, Russian Federation, shogen@inbox.ru, https://orcid.org/0000-0002-5141-3062

Anzor A. Khokonov, Candidate of Sciences (Politics), Associate Professor, Department of Political Science, Financial University under the Government of the Russian Federation, Prosp. Leningradsky, 49, 125993 Moscow, Russian Federation, dr_enzo@mail.ru, https://orcid.org/0000-0001-6371-8173

\section{Информация об авторах}

Сергей Юрьевич Белоконев, кандидат политических наук, научный руководитель Факультета социальных наук и массовых коммуникаций, Финансовый университет при Правительстве Российской Федерации, просп. Ленинградский, 49, 125993 г. Москва, Российская Федерация, departpol@mail.ru, https://orcid.org/0000-0002-8028-7421

Мурат Замирович Шогенов, кандидат психологических наук, доцент, старший научный сотрудник Центра социологических исследований, Кабардино-Балкарский государственный университет, ул. Чернышевского, 173, 360004 г. Нальчик, Российская Федерация, shogen@inbox.ru, https://orcid.org/0000-0002-5141-3062

Анзор Альбертович Хоконов, кандидат политических наук, доцент Департамента политологии, Финансовый университет при Правительстве Российской Федерации, просп. Ленинградский, 49, 125993 г. Москва, Российская Федерация, dr_enzo@mail.ru, https://orcid.org/0000-0001-6371-8173 